\title{
CarbonCulture at DECC: Digital Engagement for Sustainability at Work
}

\author{
Dan Lockton \\ WMG, University of Warwick, \\ Coventry, and Brunel Design \\ Research Centre, \\ Brunel University, London \\ dan@danlockton.co.uk
}

\author{
Rebecca Cain \\ WMG, University of \\ Warwick, Coventry \\ R.Cain.1@warwick.ac.uk
}

\author{
David Harrison \\ Brunel Design Research Centre \\ Brunel University, London \\ David.Harrison@brunel.ac.uk
}

\author{
Luke Nicholson \\ More Associates \\ London \\ luke@moreassociates.com
}

\begin{abstract}
This paper reports on CarbonCulture at DECC, an employee engagement platform for sustainable behaviour, which took place at the Department of Energy \& Climate Change in London. Through a participatory design process, we developed simple web apps enabling staff to log actions around late working, food choices and commuting, and see colleagues' actions, providing a digital interface linking physical and spatial behaviour. We achieved a high level of engagement $(16 \%$ of staff used the apps) and identified patterns of user engagement to inform future development.
\end{abstract}

Keywords: energy, sustainability, carbon, behaviour change, engagement, workplaces.

\section{INTRODUCTION}

Sustainable $\mathrm{HCl}$ is a rapidly growing applied subdiscipline (DiSalvo et al, 2010) addressing, as considered by Mankoff et al (2007), both sustainability in design and sustainability through design. Sustainability through design often takes the form of interventions aiming to change users' behaviour-making lifestyle changes and influencing interaction with products and systems. This can be about adopting new systems, or using existing ones more efficiently (Lockton et al, 2009), individually or in groups.

Given the importance of physical products and the built environment in $\mathrm{CO}_{2}$ emissions, the broader scope of the Internet of Things has much potential, offering meaningful connections between physical and digital interaction, and new opportunities for generating and interpreting both quantitative and qualitative data. Sustainable $\mathrm{HCl}$ and design for sustainable behaviour have become the focus of a range of projects which can broadly be considered in this category; most centre on reduced $\mathrm{CO}_{2}$ emissions through influencing energy use and transport choices (e.g. Cowan et al, 2013; Foster et al, 2011, Froehlich et al, 2009).

Reducing household $\mathrm{CO}_{2}$ emissions through behaviour change (e.g. Lockton et al, 2013a) is considered a major priority, including at government level (Cabinet Office Behavioural Insights Team, 2011; Dietz et al, 2009), but nondomestic emissions also offer opportunities. For example, $\mathrm{CO}_{2}$ emissions arising from non-domestic buildings-primarily workplaces-make up $18 \%$ of the UK's footprint (Technology Strategy Board,
2009); while infrastructure and operating changes can lead to major efficiency gains, staff behaviour is also "a key determinant of energy consumption" (Hadi \& Halfhide, 2009). Thus, interventions to address staff behaviour are increasingly commonoften communication-led, drawing on social marketing, though some approaches use persuasive technology and allied $\mathrm{HCl}$ perspectives, e.g. via feedback and visualisation (Pierce \& Paulos, 2012). Organisational motives include cutting energy bills (and 'carbon tax' in some countries) and wider benefits such as increasing overall employee engagement.

\section{THE CARBONCULTURE AT DECC PROJECT}

The UK's Department of Energy and Climate Change (DECC) aims to lead by example in its own building in central London. Technical efficiency improvements led to a $21.3 \%$ reduction in $\mathrm{CO}_{2}$ emissions in 2010-11, but DECC has recognised that further improvements will come in part through behaviour change. CarbonCulture at DECC, introduced in this paper, comprises a range of lowcost $\mathrm{HCl}$-led interventions developed through a pilot study at DECC's offices (c.1,000 staff), by an external team (CarbonCulture team \& DECC, 2012).

Our aim was to develop effective methods of engaging employees in understanding and caring about the part their behaviour plays in $\mathrm{CO}_{2}$ emissions, both as a precursor to behaviour change, and to increase 'buy-in' to relevant building operation changes. Many techniques for influencing 
behaviour through design have been recognised (Lockton et al, 2010) and applied in domains such as health as well as sustainability; gamification (Deterding et al, 2011), behavioural economics and the quantified self (Munson et al, 2012) are approaches currently receiving significant attention. With CarbonCulture we adopted elements of these as part of a participatory design methodology, involving DECC employees in development through workshops and iterative prototyping.

DiSalvo et al's (2010) distinction between seeing "users as the problem" and "solving users' problems" is useful here; solving users' problems through more sustainable behaviour seems preferable for engagement. (This does assume that engagement is the answer to more sustainable behaviour, which is, however, not necessarily the whole story (Stern, 2000)). Could we engage large numbers of people, in one building, in voluntary carbon-saving behaviours by making them useful, fun and rewarding? Workplaces and households offer some different challenges for behaviour change; at DECC, there were also political considerations such as avoiding the perception of 'bonus' incentives using taxpayers' money. On the other hand, some DECC staff were already betterinformed on environmental issues than the general population.

\section{THE ELEMENTS OF THE PROJECT}

The project started with user research via interviews, workshops and the use of simple physical touchpoints, to identify both behaviours which it would be possible to address, and the kinds of tools which would be useful.

\subsection{Physical touchpoints}

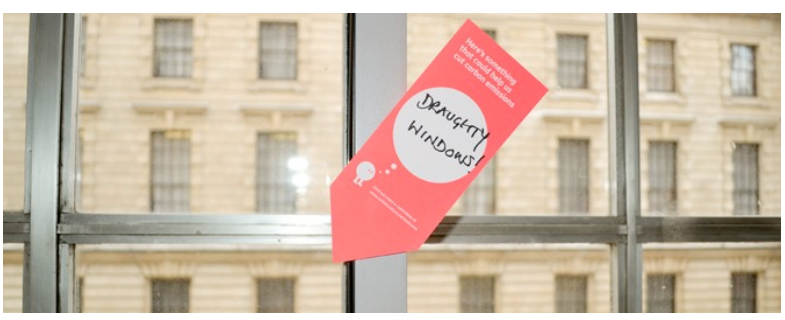

Figure 1: 'Arrows' with which staff annotated the building

Activities included asking employees to 'annotate' their working environment with 'arrow' comment cards (Figure 1) to raise issues around $\mathrm{CO}_{2}$ impact and encourage participation.

Comments on the arrows highlighted details of everyday interactions: for example, that the building's lifts are controlled by two separate circuits with two buttons on each floor; people habitually press both to try to get a lift quickly, meaning that both lifts respond each time.

One of the aims here was to help make visible some of the 'invisible' links between systemsincluding the positions of sensors which provided input to the building management system-and provide a tangible starting point for exploring staff's mental models of the systems around them. For example, the prevalence of staff interest in (and confusion over) the heating and air conditioning systems, revealed through the arrows exercise, led to exploring behavioural heuristics around heating and cooling (Lockton et al, 2013b).

\subsection{The digital platform}

The main focus of the project was a digital platform, supporting a number of web apps, user dashboards, an internal blog, and near-realtime electricity and gas use visualisations. The apps were developed via workshops with staff and with quantification of the $\mathrm{CO}_{2}$ reductions possible through different behaviour changes, andapplying a relatively simple game mechanicoffered users points for logging particular actions, which could be collected and redeemed for a limited number of 'sustainable' prizes (so the 'most engaged' people were closest to winning when prizes were announced).

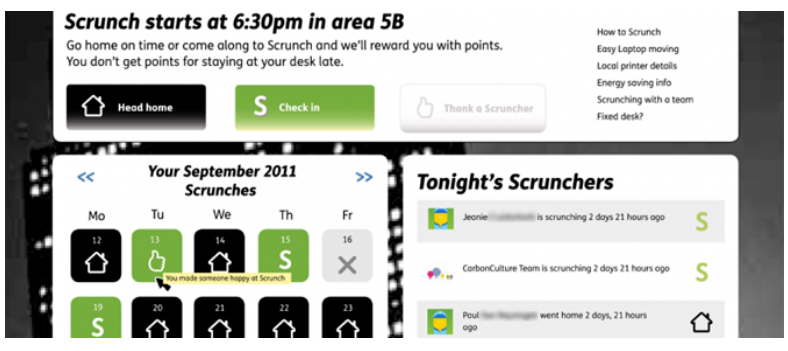

Figure 2: Scrunch: 'social proof' activity feed and calendar

\subsubsection{Scrunch: Your comfortable evening working space}

The DECC building has seven floors, with a majority of staff hot-desking. Keeping lights on outside office hours in case people are working late is expensive and wasteful. The Scrunch app (Figure 2) aimed to reduce the 'size of the office' to the (quite small) size of the workforce outside of normal work hours, by encouraging staff to move to a single 'Scrunch' floor. Staff received points for logging 'heading home' or checking in on the Scrunch floor, and a 'social proof' ticker showed colleagues' actions. The 'head home' option was rewarded equally, since taking part is fundamentally what mattered; the focus was on user engagement to encourage moving floor, or going home. 
Barriers identified through the workshops included statements such as "I'll only be here another 15 minutes, I promise" and "I have to shut down my laptop and restart it again, which takes ages." To address the first barrier, we differentiated between staff finishing work and leaving soon, and those who would be working late. The process of undocking and re-docking laptops was made easier through creating simple (laptop-shaped) postcards explaining very simply how to do it without requiring a full shutdown-a conversation-starter initially aimed at Scrunchers, but which became a useful tool for all DECC staff. The designated 'Scrunch' floor was made appealing through free cakes and tea, with printers also set up to make the move easier; the aim was to make the environment better than staying put, with the app providing support and allowing tracking as well as rewards.

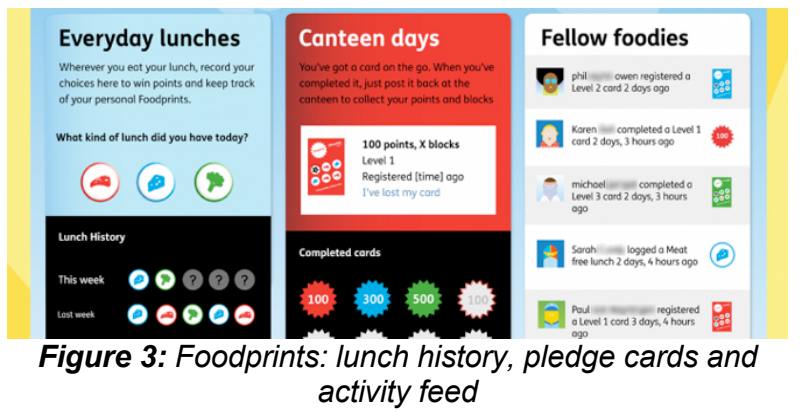

\subsubsection{Foodprints: Healthier lunches, lower carbon}

In the UK, food can represent $20 \%$ of an individual's carbon footprint (Sustainable Development Commission, 2009); this can be cut by eating less meat and dairy, which can also be healthier. The Foodprints app enabled staff to log their lunchtime choices in the DECC canteen (Figure 3), providing both personal 'diet' and 'sustainability' tracking, together with printed 'pledge cards' which canteen staff would stamp with each meal.

Equal points were awarded for the action of logging-not for the meal choice-but some game mechanics were used to maintain continued engagement, such as 'Hidden Treasure' (where extra points were hidden somewhere in the lunch recording tool for that week) and ' 5 in a row' (extra points for completing the recording for a whole week). The cards provide the opportunity for verification by canteen staff, enabling different point levels to be introduced at a later date if desired.

\subsubsection{OK Commuter: How was your journey today?} Transport choices are a significant factor in $\mathrm{CO}_{2}$ emissions. With DECC's central London location, few staff live nearby and most commute using train, tube or bus. Many cycle or walk; driving is difficult and parking expensive. Hence, transport choices are already mostly lower-carbon than at many other workplaces. However, there are still benefits of a

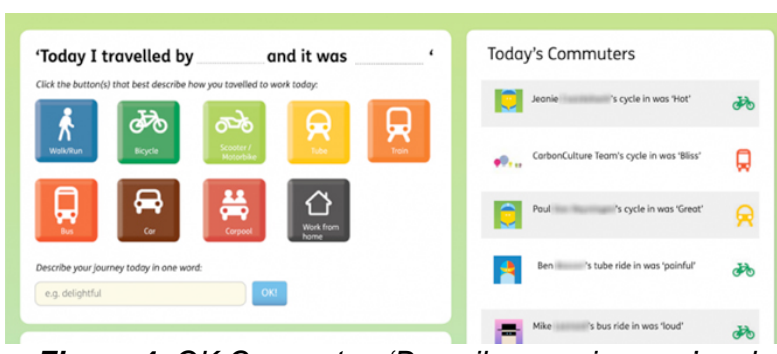

Figure 4: OK Commuter: 'Describe your journey' and activity feed (journey history not shown here)

recording tool for the commute, and behaviours may still be changed-for example, encouraging more walking and cycling, with attendant health benefits. The action of logging each day's journeys, and visualisation of the past month's travel, can maintain engagement, and this function was built into the OK Commuter app (Figure 4), with points awarded for logging. The app included daily visualisations of the transport modes used as well as a live 'social proof' activity feed.

We found from early workshops that many staff who cycle, in particular, are often proud of their commitment, and showing this to colleagues via the feed capitalised on this. Equally, though, most people use the same form of transport every day, reducing the personal interest in logging it. We thus introduced a 'creative description' field encouraging users to 'tag' each journey with a short (often witty) comment-for example, "Maria A's bus ride in was: Smelly" or "Brian F's cycle in was: Blissful". This maintained engagement as well as providing a playful talking point among colleagues.

\subsubsection{Other apps}

Two other apps were prototyped: 'GO2', dealing with business travel, and 'Thermopeople', dealing with thermal comfort, but the audience and potential $\mathrm{CO}_{2}$ impact at DECC was small due to contextual factors of the organisation and building management. The impact could be larger elsewhere.

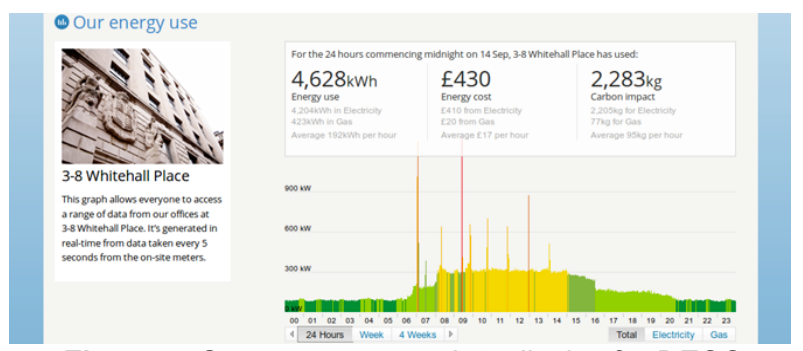

Figure 5: Summary energy data display for DECC building

\subsubsection{Energy visualisation}

Visualisations of the DECC building's electricity and gas use were also made available under the CarbonCulture banner (Figure 5), both 5-second data and daily/weekly/monthly, with kWh, costs and $\mathrm{CO}_{2}$ given. This ongoing component demonstrated a link between the behavioural aspects of the apps, 
and the overall impact of the building, as well as enabling seasonal trends to be discussed more clearly through the internal blog. It also enabled DECC's facilities managers to identify-and implement-savings in gas use of around $10 \%$ through changing water heating schedules, not through staff behaviour change, but useful nonetheless. As well as via users' CarbonCulture dashboards, the visualisations were (and are) publicly accessible via the open web at http://carbonculture.net/orgs/decc

\section{RESULTS AND DISCUSSION}

We ran the pilot study at DECC in the last quarter of 2011, with apps introduced over time. Scrunch was the first to be launched, following the earlier workshops, arrows and blog posts. Of 1,000 staff at DECC, 412 voluntarily signed up to CarbonCulture, establishing a total membership for the programme of around $40 \%$. While figures for comparable internal programmes are difficult to obtain, these compare very favourably with, for example, $13 \%$ of eBay employees signed up to the 'Green Team' and $15 \%$ of US employees signed up to BT's solar education programme (Bin, 2011). Of the CarbonCulture membership, 166 used at least one app, representing again $40 \%$ 'engagement' of members. Overall, then, $16 \%$ of all staff used the apps.

DECC staff 'Scrunched' 81 times, and used the 'Head Home' button 1,561 times. With Foodprints, 2,747 lunches were logged and 110 cards registered. OK Commuter users logged 2,229 journeys. Aggregate figures hide the detail, of course, but by analyzing individual users' behaviour (and users' comments) we identified some patterns of engagement and retention, as users were attracted or incentivised by different elements-for example, some competed or collaborated with immediate colleagues to earn points (and prizes), while others used the logging features primarily for their own interest. Some collected sufficient points but never claimed prizes. Although 123 users of the 166 used all three apps at least once, many users stuck with only one or two of them.

Adding additional apps over time led to uplifts in user numbers, and we believe that this can provide a sustainable mechanism to attract and retain users by keeping them interested in fresh new tools, as well as attracting new staff to the platform as colleagues sign up. However, it makes statistical comparisons more difficult.

Scrunch has a high initial barrier, but also a high reward of carbon reduction to match, if used at capacity. Foodprints offers a medium barrier to engagement (everyone has to eat), and a high potential of carbon savings, although these don't produce direct energy savings in the building.
Finally, OK Commuter has a low initial barrier, but acted mainly as a baselining tool: the substantial carbon savings available would have to be accessed in a future development through specifically enabling and encouraging changes to transport choice.

As well as quantitative data on user actions, users provided qualitative feedback on their experience. This was continued with in-depth user interviews as the pilot came to a close.

It is likely, of course, that DECC staff were already generally interested in energy and environmental issues, and so perhaps easier to engage. Running CarbonCulture at other organisations will need to address different issues, both in terms of $\mathrm{CO}_{2}$ impact and staff culture, but we believe the basic platform is flexible enough to achieve this, in conjunction with a participatory design process.

One question worth considering is around the longer-term sustainability of this kind of intervention. Was the degree of engagement, and staff's motivation, dependent on the points? Did attitudes and awareness change permanently? A few quotes from DECC staff as the pilot came to a close suggest some effect, e.g. "It has changed my behaviour: I am car-pooling to work with a colleague", but a longitudinal study would be needed to assess the effects in the longer term.

\section{CONCLUSIONS}

In the Sustainable $\mathrm{HCl}$ field, burgeoning with projects addressing sustainable behaviour, our contribution is a demonstration of engaging employees around behavioural sustainability, via a digital platform. The CarbonCulture platform employs similar features (logging actions, awarding points, showing other users' actions in an activity feed) across three apps targeting different behaviours, all linked to elements of the physical environment.

We achieved a high level of engagement, and while the project ran for only three months, we found that while the aspects which engaged users differed, together they addressed multiple motivations. Adding and improving apps over time was an important component in maintaining engagement.

As the pilot's focus was understanding how to drive engagement rather than behaviour change itself, we cannot say that the pilot led to reducing DECC's emissions, but what was learned will enable future versions of CarbonCulture to be deployed with behaviour change more specifically the goal, translated into measurable impacts on carbon. Commercially, a similar CarbonCulture programme is in development for universities and a property management and construction group. The 
platform will also be used for a behaviour change project in the UK Parliament itself.

Aside from the apps, the energy visualisation component facilitated communication between building users and building management teams, and helped staff gain some more understanding of the systems around them-which may be a potential benefit of Internet of Things-type approaches more broadly. The displays we developed and used at DECC have now been deployed across eight UK government departments (including 10 Downing Street), Tate Modern, and Cardiff Council's estate.

\section{ACKNOWLEDGEMENTS}

Thanks to DECC participants, and the communications and estates teams. The project was part-funded by the Technology Strategy Board under the 'EMPOWER' title.

\section{REFERENCES}

Bin, S. (2011). Greening Work Styles: An Analysis of Energy Behavior Programs in the Workplace. American Council for an Energy-Efficient Economy, Washington, DC.

Cabinet Office Behavioural Insights Team (2011). Behaviour Change and Energy Use. Cabinet Office, London.

CarbonCulture team \& DECC (2012). How can user engagement save energy and carbon at work? Department of Energy \& Climate Change, London.

Cowan, B.R., Bowers, C.P., Beale, R, \& Pinder, C. (2013). The Stroppy Kettle: An Intervention to Break Energy Consumption Habits. CHI 2013, Paris, ACM, New York.

Deterding, S., Dixon, D., Nacke, L. E., O'Hara, K., \& Sicart, M. (2011) Gamification: Using Game Design Elements in Non-Gaming Contexts. CHI 2011, Vancouver, ACM, New York.

Dietz, T., Gardner, G.T., Gilligan, J., Stern, P.C. \& Vandenbergh, M.P. (2009). Household actions can provide a behavioral wedge to rapidly reduce U.S. carbon emissions. Proceedings of the National Academy of Sciences 106(44), $18452-18456$

DiSalvo, C., Sengers, P. \& Brynjarsdóttir, $H$. (2010). Mapping the landscape of sustainable HCl. CHI 2010, Atlanta, ACM, New York, 19751984.

Foster, D., Linehan, C., Lawson, S. \& Kirman, B. (2011). Power ballads: deploying aversive energy feedback in social media. CHI 2011, Vancouver, ACM, New York, 2221-2226

Froehlich, J., Dillahunt, T., Klasnja, P., Mankoff, J., Consolvo, S., Harrison, B. \& Landay, J.A. (2009). UbiGreen: investigating a mobile tool for tracking and supporting green transportation habits. CHI 2009, Boston, ACM, New York, 1043-1052

Hadi, M. \& Halfhide, C. (2009). The move to lowcarbon design: are designers taking the needs of building users into account? BRE, Watford, UK.

Lockton, D., Harrison, D. \& Stanton, N. A. (2009). Design for Sustainable Behaviour: investigating design methods for influencing user behaviour. Sustainable Innovation 09: Towards Sustainable Product Design 14, Farnham, UK, Centre for Sustainable Design

Lockton, D., Harrison, D. \& Stanton, N.A. (2010). The Design with Intent Method: a design tool for influencing user behaviour. Applied Ergonomics 41(3), 382-392

Lockton, D., Bowden, F., Greene, C., Brass, C. \& Gheerawo, R. (2013a). People and energy: A design-led approach to understanding everyday energy use behaviour. EPIC 2013: Ethnographic Praxis in Industry, Royal Institution, London

Lockton, D., Harrison, D., Cain, R., Stanton, N.A. \& Jennings, P. (2013b). Exploring problem-framing through behavioural heuristics. International Journal of Design 7(1), 37-53.

Mankoff, J.C., Blevis, E., Borning, A., Friedman, B., Fussell, S.R., Hasbrouck, J., Woodruff, A. and Sengers, P. (2007). Environmental sustainability and interaction. CHI 2007, San Jose, ACM, New York, 2121-2124.

Munson, S.A. (2012). Mindfulness, Reflection, \& Persuasion in Personal Informatics. Personal Informatics Workshop. CHI 2012, Austin: http://personalinformatics.org/docs/chi2012/mun son.pdf

Pierce, J. \& Paulos, P. (2012). Beyond energy monitors: interaction, energy, and emerging energy systems. CHI 2012, Austin, ACM, New York, 665-674

Stern, P.C. (2000). Toward a coherent theory of environmentally significant behavior. Journal of Social Issues 56, 407-424

Sustainable Development Commission (2009). Setting the Table: Advice to Government on Priority Elements of Sustainable Diets. Sustainable Development Commission, London.

Technology Strategy Board (2009). User-centred design for energy efficiency in buildings. Technology Strategy Board, Swindon. 